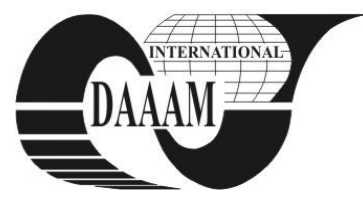

Annals of DAAAM for 2011 \& Proceedings of the 22nd International DAAAM Symposium, Volume 22, No. 1, ISSN 1726-9679 ISBN 978-3-901509-83-4, Editor B. Katalinic, Published by DAAAM International, Vienna, Austria, EU, 2011 Make Harmony between Technology and Nature, and Your Mind will Fly Free as a Bird Annals \& Proceedings of DAAAM International 2011

\title{
COMPUTER BASED EDUCATIONAL MODEL OF THE BENT HULL IN THE CONTEXT OF THE MARITIME EDUCATION
}

\author{
OANTA, E[mil]; PANAIT, C[ornel]; BATRINCA, G[hiorghe] \& PESCARU, A[lexandru]
}

\begin{abstract}
The paper presents an original solution to enhance the technical education of the students who will become maritime officers. Taking into account the gap between the general topics and those dedicated to their specialization, among other solutions, we present a relevant computer-based educational model of the ship's hull which is solved using the ship strength methods. Even the solution might be considered complex, the model can be understood by the students because it uses notions from the topics previously completed by them: mathematics, computer programming and numerical methods. The according original software consists of more than 11400 computer code lines. It can be also used in design or research problems as an initial analytic solution.
\end{abstract}

Key words: mechanical engineering, educational model, algorithm, original software, research instrument

\section{INTRODUCTION}

In the actual global conditions all the job markets became international markets. Among them, the maritime officers' job market has some important features, such as:

- the onboard personnel is well payed because they have important responsibilities;

- there are very many vacancies in the international fleet;

- there are demands of the shipping companies to offer lower salaries, so they are oriented to Far East countries where people accept such salaries.

The solution of the shipping companies is to have fewer but better educated maritime officers, who must be well payed, in order to take all the sailing and the technical responsibilities.

Accordingly, we must educate in a proper way our students in order to be competent in their onboard jobs and also at a later stage, when they will attend off-shore positions.

\section{PROBLEM STATEMENT}

Maritime education has specific features. Graduates are maritime officers who are in charge with well specified onboard tasks. No matter the severe weather conditions or other threats, they must elaborate the right decisions in a brief period of time, taking into account various parameters and possible scenarios. In this field accidents have serious consequences consisting of losses of lives and/or cargo, pollution, damage of the ship, and other. This is why the university level education of the maritime officers must meet specific international requirements.

Maritime transport is supervised by the International Maritime Organization (IMO). The training of the future maritime officers is based on the Standards of Training, Certification and Watchkeeping (STCW), which specifies the minimum knowledge required for a maritime officer. This was necessary because, regardless the country where the officer was trained, the problems are the same at international level.

Moreover, if the graduates are also engineers, there must be respected the rules of the Romanian Agency for Quality Assurance in Higher Education (ARACIS).
The problem is how to imagine the best methods in maritime education in order to respect all the above mentioned constraints.

\section{COMMON USE SOLUTIONS}

Regarding the education which must respond to the maritime training demands, there are several solutions: - It was created a curricula based on the STCW specifications; - Maritime training starts in the university, where the students use several simulators in order to become more experienced;

- Practical activities at sea consisting of 12 months of training are compulsory;

- Specific IMO courses were offered to the students who want to become maritime officers, additional to the basic curricula.

On the university education side, the measures were:

- English is a topic extensively included in the curricula; - Physical education is dedicated to the nautical sports and to the necessities of training of the onboard personnel.

Regarding the topics which have a general technical background, like strength of materials, the theoretical aspects presented to the course are general and in accord with the ARACIS rules, while the applications are using models of the onboard equipment which will be used by our graduates.

\section{ORIGINAL SOLUTION}

Along the years it was noticed a gap between the general topics and the technical topics to be studied in the $3^{\text {rd }}$ and $4^{\text {th }}$ years of university studies. Some of the measures to connect the general topics to the practical aspects were:

- Creation of a large multimedia library which is used to present the design of several onboard equipment: the basic underlying concepts, to discuss the technical solutions (strengths and weaknesses) and to imagine other possible solutions, etc.;

- Examples of accidents where the use of the technical knowledge would avoid the according severe consequences;

- Study of a large number of examples in order to make the students notice the features of the technical phenomena, to make them acquire experience and finally, to educate their common sense in technical (and scientific) problems.

This last aspect was carried out by the use of several original software applications created by us, solution which is compatible with the actual trends based on artificial intelligence (Galea \& Leon, 2010) and on numerical methods solutions (Demidovitch \& Maron, 1979) customized to fit our problems.

\section{CASE STUDY: MODEL OF THE SHIP'S HULL}

One of the most important problems is about the structural integrity of the hull of the ship. As we know, basically, the ship is subjected to weight and Archimedean loads. Because it is hard to evaluate the law of variation of these loads along the hull, the structure is divided into intervals for which the weight and the Archimedean force are far easier to asses. 
Figure 1 presents the hull divided in intervals, the position of the forces for each interval, the cross-section of the hull and the use of the Bonjean curve for the calculus of the Archimedean force. This idea regarding the method to divide the calculus domain was previously used in mathematics where the result of the integration of a one variable function is the area between the graph and the $\mathrm{X}$-axis, this area being geometrically computed as a set of rectangles or as a set of trapezia.

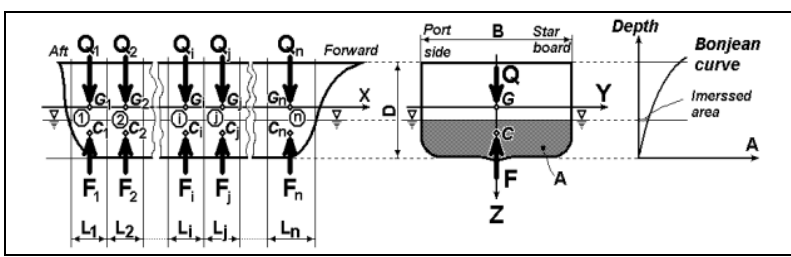

Fig. 1. Calculus pattern for a ship's hull

Then we consider the according distributed forces computed with the relationships:

$$
q_{i}=\frac{Q_{i}[k N]}{L_{i}[m]} ; \quad f_{i}=\frac{F_{i}[k N]}{L_{i}[m]} ; p_{i}=q_{i}-f_{i}
$$

It results a model of a straight beam loaded with distributed forces, presented in the next figure.

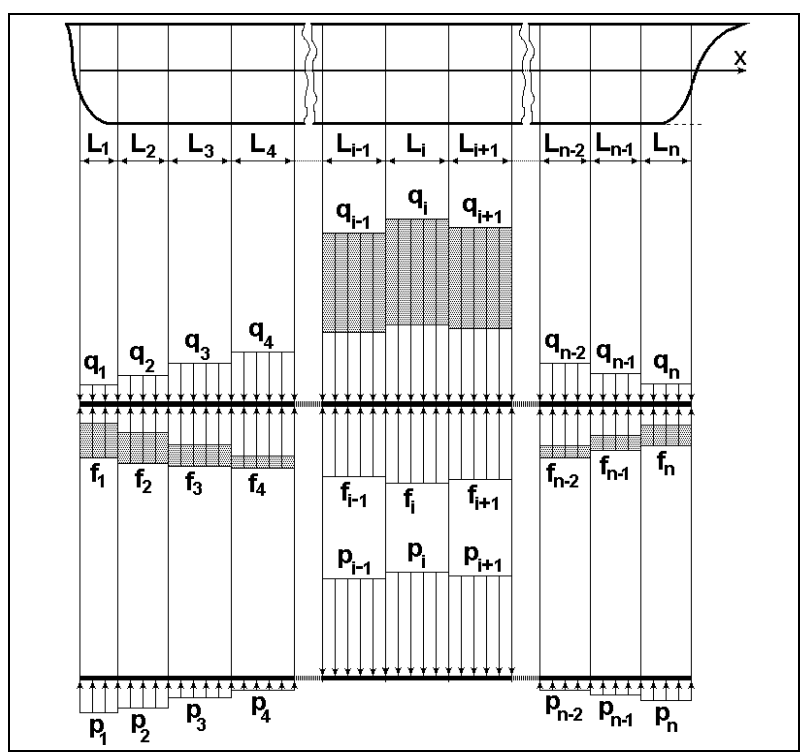

Fig. 2. Distributed forces applied on the model

For a general located interval, whose calculus pattern is presented in figure 3 , there must be computed the stresses and the deflections.

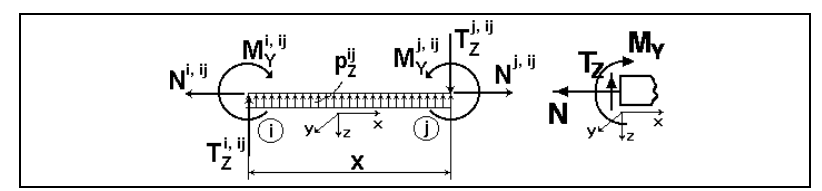

Fig. 3. Calculus pattern for a general located interval

Stresses can be computed if the internal forces and moments are known for each cross-section of the 'equivalent' beam. To compute the deflections, there must be integrated the differential equation of the neutral axis of the beam, (2),

$$
\frac{\partial^{4} u_{Z}(x)}{\partial x^{4}}=\frac{\partial^{3} \varphi_{Y}(x)}{\partial x^{3}}=-\frac{\partial^{2} M_{Y}(x)}{\partial x^{2}}=-\frac{\partial T_{Z}(x)}{\partial x}=-p_{Z}(x)
$$

According to the method of initial parameters, there are several methods to integrate the equation. The problem was solved by developing a software application consisting of more than 11400 computer code lines which offers both diagrams and laws of variation of the shear force, bending moment, rotation and deflection of the beam.

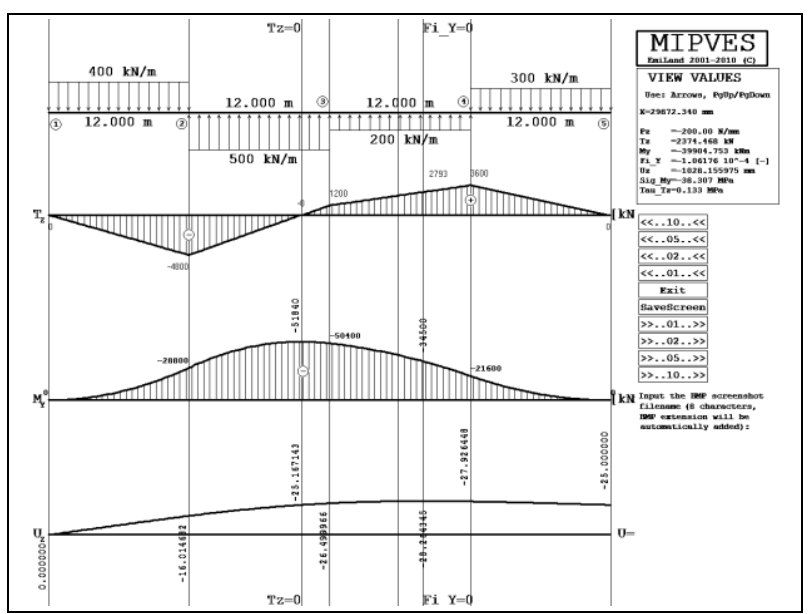

Fig. 4. Screen shot: free body diagrams and the deflected shape of the hull for an educational model

Diagrams similar to those in figure 3 are automatically generated by the simulators and by the onboard software, so the students understand now the phenomena behind the images.

\section{CONCLUSION}

Intelligent nowadays solutions use numerical methods, algorithms and computer programming (Knuth, 2000). Solving these problems is a long run concern (Oanta, 2000) and the intelligent design of the according software (Oanta \& Nicolescu, 2002) offers the opportunity to reuse, upgrade and extend it. This idea was employed in the development of modern computer based analytic models which can be easily improved in terms of accuracy and flexibility. One can notice that the same computer based solutions can be used in all: education, design and research, following the actual trend to embed more intelligence and information in our instruments.

\section{ACKNOWLEDGEMENTS}

Several of the ideas presented in the paper are the result of the models developed in the framework of the scientific research study 'Development of computer assisted marine structures', Emil Oanta, Cornel Panait, Ghiorghe Batrinca, Alexandru Pescaru, Alexandra Nita, Feiza Memet, which is a component of the RoNoMar project, 2010.

\section{REFERENCES}

Demidovitch, B.; Maron, I. (1979), Elements de calcul numerique, Editions Mir, Moscou

Galea D.; Leon F. (2010), Artificial intelligence - online course, "Gh. Asachi" Technical University, Faculty of Automatic control and Computer Engineering, Available from: http://eureka.cs.tuiasi.ro/ fleon/curs_ia.htm, Accessed: 2010-07-05

Knuth, D. (2000), The art of computer programming, 3rd edition, vol 1, Teora Publishing House, ISBN 973-601-9101, Bucharest

Oanta, E. (2000), Basic theoretical knowledge in programming the computer aided mechanical engineering software, Andrei Saguna Publishing House, ISBN 973-8146-04-6, Constanta

Oanta, E.; Nicolescu, B. (2002), ESDA2002/APM024: MIPVES - Software which employs the method of initial parameters applied for vessels, Proceedings of ESDA 2002: 6th Biennial Conference on Engineering Systems Design and Analysis, Istanbul, July 08-11, 2002, Istanbul, Turkey 